\title{
DÖNÜ KARARLI MERMİLERDE SÜRÜKLENME KATSAYISININ ŞEKİL FAKTÖRÜ AÇISINDAN DENEYSEL VE SAYISAL OLARAK İNCELENMESİ
}

\author{
Muammer AKÜZÜM ${ }^{1}$, Cevdet AYGÜN ${ }^{2}$ \\ ${ }^{1}$ Kara Harp Okulu, Makine Mühendisliği Bölümü, 06654, Çankaya, Ankara \\ ${ }^{2}$ Gazi Üniversitesi, Mühendislik Fakültesi, Makina Mühendisliği, Bölümü, 06570, Maltepe, Ankara \\ makuzum@kho.edu.tr, caygun@gazi.edu.tr
}

(Geliş/Received: 13.01.2016; Kabul/Accepted: 08.03.2016)

\begin{abstract}
ÖZET
Sunulan çalışmada 7,62x51 mm NATO mermisi örnek alınmış ve farklı geometrilerdeki mermilerin sürüklenme katsayılarını $\left(C_{D}\right)$, minimize etmek amacıyla deneysel ve sayısal olarak incelenmiştir. Deneyler için G3 piyade tüfeği, B481 model Doppler radarı ve veri toplama sistemi kullanılmıştır. Sayısal analizler balistik hesaplamalarda siklıkla kullanılan ve geometrik optimizasyon uygulayarak sayısal hesaplama yapma kabiliyetine sahip PRODAS programı ile gerçekleştirilmiş̧ir. Mevcut mermi geometrisi için kullanılan referans değerler deneysel ve sayısal olarak doğrulanmıştır. Daha sonra doğrulaması yapılan mermi üzerinde belirlenen parametrelerde değişiklikler yaparak farklı mermi numuneleri hazırlanmıştır. Hazırlanan numuneler aynı ağırlıkta barut ile doldurulduktan sonra fişek haline getirilerek deneysel olarak test edilmiştir. Mermi numuneleri hazırlanırken mevcut mermi modeli üzerinde temel ölçülerden mermi çapı, merminin orta bölümünün fişek ile birleştiği uzunluk ve mermi radyüsünün başladığı yerden burun başlangıç noktasına kadar olan uzunluk değerleri korunmuştur. Hazırlanan yeni mermiler için sürüklenme katsayıları $\left(C_{D}\right)$ ses altı ve ses üstü hızlarda deneysel olarak ölçülmüş ve PRODAS programı ile sayısal olarak hesaplanmıştır.
\end{abstract}

Anahtar Kelimeler: Sürüklenme katsayısı, mermi, şekil faktörü, prodas, doppler radar, sesaltı ve sesüstü hızlar

\section{THE EFFECT OF SHAPE FACTOR ON THE DRAG COEFFICIENT OF SPIN STABILIZED BULLETS BY EXPERIMENTAL AND NUMERICAL ANALYSES}

\begin{abstract}
In the present study, $7.62 \times 51 \mathrm{~mm}$ NATO bullet has been taken as an example and drag coefficients $\left(\mathrm{C}_{\mathrm{D}}\right)$ of the bullets at different geometric forms have been examined experimentally and numerically, in an attempt to minimize them. A G3 infantry rifle, a B481 Doppler Radar and a data gathering system have been employed for the experiments. The PRODAS program, which is capable of implementing numerical calculations by carrying out geometric optimisation and is used frequently in ballistic calculations, has been utilized for numerical calculations. Reference values, which are utilized for the existing bullet geometry, have been verified in experimental and numerical terms. Subsequently, different forms of the bullet samples have been designed and manufactured by varying the certain geometric parameters predetermined on the bullet which had been verified as mentioned above. These samples have been filled with the same amount of the gunpowder each and turned into cartridges and tested in ballistic experiments. While designing the bullet samples, the basic dimensions consisting of the bullet diameter, the longitudinal length from the starting point of the bullet radius to the starting point of the bullet nose, and longitudinal length from the starting point of the bullet radius to the point where the cartridge starts have been maintained on the existing bullet model. The drag coefficients $\left(C_{D}\right)$ of the new bullets have been experimentally measured both at the subsonic and the supersonic speeds and they have also been numerically calculated with PRODAS program.
\end{abstract}

Keywords: Drag coefficient, bullet, shape factor, prodas, doppler radar, subsonic and supersonic velocities 


\section{GIRIŞ̧ (INTRODUCTION)}

Balistik, mermi hareketini inceleyen bir bilim dalıdır. Temel olarak dört ana başlığa ayrılır. Bunlar iç balistik, orta balistik, diş balistik ve hedef balistiğidir. İç balistik, merminin ateşlendikten sonra namlu içerisindeki hareketini inceler. Orta balistik ise merminin namlu ağzında oluşturduğu etkiyi inceler. Mermi namluyu terk ettikten sonra hedefe varıncaya kadar hava ortamındaki hareketi dış balistiğin konusudur. Hedef balistiği ise merminin hedefte meydana getirdiği etkileri inceler [1]. Bir mermi namluyu terk ettikten sonra hedefine varıncaya kadar aerodinamik açıdan birçok etkiye maruz kalmaktadır. Bu etkiler arasında mermi hızını ve menzilini en fazla olumsuz etkileyen kuvvet sürüklenme kuvvetidir [2]. Mermi üzerine gelen sürüklenme kuvveti sürüklenme katsayısı olarak ifade edilen boyutsuz bir büyüklükle ifade edilir. Sürüklenme katsayısı mermi şekline doğrudan bağlıdır. Dönü kararlı mermilerde, mermi üzerine gelen hava direnci merminin hizinda ve kararlılığında büyük düşüşlere neden olmaktadır. Bunun sonucunda mermi istenen uzaklığa istenen kararlılıkta gidememekte ve enerjisinin birçoğunu bu etkiler altında kaybetmektedir. Mermi, namluyu terk ettikten sonra mermi üzerine gelen hava direncini azaltmak için ilk olarak merminin şekli üzerine çalışmalar yapılmıştır. Bunun için öncelikle mermi geometrisi üzerine bazı iyileştirmeler yapılarak sürüklenme katsayısının azaltılmasına çalışılmıştır. İlk olarak 1866 yilında kronograf teknolojisinin mermi hızı ve uçuş süresi hesabında kullanılması ile birlikte Francis Bashforth tarafindan İngiltere'de silindirik numuneleri $130-850 \mathrm{~m} / \mathrm{s}$ hızlarda $45^{\circ}$ lik açıda ateşlenerek düştükleri yere kadar olan süre deneysel olarak belirlemeye çalışılmıştır [3]. Takip eden yıllarda 1875-1881 arasinda Becker ve Cranz Almanya'da ki Krupp askeri fabrikasında üç farklı mermi geometrisini $365-915 \mathrm{~m} / \mathrm{s}$ hızları arasında test etmiş ve mermilere ait sürüklenme katsayılarını yaptıkları deneysel çalışmalar ile ölçmüşlerdir. 1912 yılında bu çalışmalarını derleyip bir rapor halinde yayınlamışlardır [4]. General Mayevski ve Nikolai 1872 yllında Rusya'da farklı geometrilere sahip mermiler için aerodinamik katsayılar üzerine deneysel çalışmalar yapmışlardır [5]. Albay James M. Ingalls 1900 yılında Dünya üzerinde yapılan tüm bu çalışmaları içinde barındıran farklı geometrilere ait mermilerin sürüklenme katsayılarını tablo olarak yayınlamıştır [6]. Amerikan ordusu mühimmat bölümünde görevli E.E. Herrmann ise 1918 yllında başlayan çalışımlarında sürüklenme katsayısını azaltmak için mevcut mermiler üzerinde geometrik iyileștirmeler yaparak $G_{1}$ adını verdiği ve günümüz mermi formlarına benzeyen ilk mermi geometrisi bulmuştur [7]. 1922 ve 1925 yilları arasında H.P. Hitchcock mermi üzerine etkiyen sürüklenme kuvvetini azaltmak için $G_{1}$ mermisine oranla daha konik forma sahip olan $G_{2}$ ismini verdiği mermi modelini oluşturmuştur. Ayrıca 1929-1931 yıllarında ise hava direncini daha da azaltmak için $\mathrm{G}_{5}$ ve $\mathrm{G}_{6}$ adını verdikleri iki farklı mermi geometrisi daha tasarlamıştır. Tüm mermileri $200-930 \mathrm{~m} / \mathrm{s}$ hızlarda deneysel testlerini yaparak 1935 yılında çalışmalarını yayınlamıştır [8]. 1940 yıllında İngiliz ordusundaki dış balistik bölümünde yapılan çalışmalarda konvansiyonel silahlar için tasarlanan kuyruk açısı $7^{\circ}$ olan mermi geometrisi $\left(\mathrm{G}_{7}\right)$ ve ağır toplar için tasarlanan $\left(\mathrm{G}_{8}\right)$ mermi geometrisi $0,5-2,8$ Mach hızlarında aerodinamik testleri yapılarak geometrik olarak optimize edilmiştir [9]. 1953 yllında C.H. Murphy farklı mermi geometrilerinde şekilsel iyileştirmeler yaparak mermiye etkiyen sürüklenme katsayısını ve dinamik dengelenmesini deneysel ölçümler yaparak incelemiştir [10]. Chapman ve Kirk 1970 y1lında mermi hareketini ifade eden alt1 serbestlik dereceli diferansiyel denklemleri çözerek mevcut deneysel sonuçlar ile karşılaştırmışlar [11]. Günümüzde de mermi hareketleri incelenirken hala bu denklem çözümleri kullanılmaktadır. R.H. Whyte General Electric firması için 1969 yılında geliştirmeye başladığı ve 1973 yılında tamamladığı SPINNER isimli bilgisayar kodu ile dönü kararlı mermiler için son 25 yılda yapılan deneysel çalışmaları ve teorileri kullanarak oluşturduğu, geometrik benzeşimi temel alan sayısal çözücü ile farklı mermi geometrileri için aerodinamik katsayıları gerçeğe oldukça yakın hesaplayabilmiştir. Bu kod daha sonra iç balistik kodlarının da eklenmesiyle ticari bir yazılım olarak PRODAS (Projectile Design and Analysis System) ismiyle bu alanda çalışan diğer kullanıcılarla paylaşılmıştır [12]. Bilgisayar teknolojisinin gelişmesi ile birlikte Navier-Stokes denklemlerinin sayısal olarak çözülmesi kabiliyeti elde edilmişsir. Bunun ardından, 1988 yilında C.J. Nietubicz ve W.B. Sturek farklı geometride mermiler için transonik ve ses üstü hızlarda sayısal analizler yapmış ve bu mermilerin farklı kuyruk açıları altında rüzgâr tünelinde testler icra edilerek bulunan deneysel sonuçlarını, hesaplanan sayısal analiz sonuçları ile karşılaştırmışlardır [13]. 1995 yılında R.M. Cummings vd., ses üstü türbülanslı akış ortamlarındaki mermilerin sayısal analizlerini yapmış ve bunlara sürükleme optimizasyonu uygulayarak farklı tasarımlar geliştirmişlerdir [14]. Yanguan Chen vd., mermi üzerindeki radyüs değerlerini değiştirerek tasarladıkları yeni mermilerin sürüklenme katsayılarını doppler radarı ile deneysel olarak ölçerek en uygun mermi geometrisini bulma çalışması yapmışlardır [15]. 2015 yilında Wanchai Jiajan vd., $155 \mathrm{~mm}$ top mermisinde, 1,8-4 Mach hızlarındaki farklı mermi geometrileri için hem sayısal hem de deneysel olarak aerodinamik katsayıların hesaplanması çalışmasını gerçekleştirmişlerdir [16]. $\mathrm{Bu}$ çalışmada ülkemiz envanterinde bulunan $7,62 \times 51$ mm NATO mermisi üzerinde geometrik değişikler yaparak mevcut üretim yöntemleri ile üretilebilecek en küçük sürüklenme katsayısına sahip mermi geometrisini oluşturmak hedeflenmiştir. Bunun için, öncelikle mevcut mermi geometrisi için standart 
olarak kullanılan sürüklenme katsayısında ki referans değerler deneysel ve sayısal olarak doğrulanmış, ardından parametrik değiştirme yoluyla tasarlanan diğer mermi geometrilerinin, sürüklenme katsayısı üzerindeki etkisi incelenmiştir.

\section{DENEYSEL ÇALIŞMA (EXPERIMENTAL STUDY)}

\subsection{Deney Sistemi (Experimental Setup)}

Sunulan çalışmada, sürüklenme katsayıları balistik ölçümlerde sıklıkla kullanılan B481 Doppler radarı ile ölçülmüştür. Deneylerde kullanılan radar sistemi 5,56 mm'den başlayarak 40 mm'ye kadar olan mühimmatlarda, $20 \mathrm{~m} / \mathrm{s}$ ile $2000 \mathrm{~m} / \mathrm{s}$ aralıklarında değişen hılarda \% 1 hassasiyet ile ölçüm yapabilmektedir. $\mathrm{Bu}$ radar tipinin seçilmesindeki temel amaç, mevcut veri toplama sistemi ile uyumlu olarak bir bilgisayar yardımıyla yüksek hızda veri aktarılmasının sağlanmasıdır. Yararlanılan veri toplama sistemi 24 bit ve 16 kanallı olup dinamik ölçüm aralığı 138 dB' dir. G3 piyade tüfeği ile yapılan test atışlarında tüfek $45^{\circ}$ 'lik açıda sabit tutulmuş ve mermiler tek tek ateşlenmiştir. Deney düzeneği Şekil 1 'de gösterilmiştir. Merminin balistik menzilini maksimize etmesi nedeniyle testlerde $45^{\circ}$ 'lik atış açısı seçilmiştir. Deney sistemine ait görüntü Şekil 2'de ki resimde verilmiştir. Doppler radarı, fişek ateşlendikten sonra mermi namluyu terk eder etmez ölçüm almaya başlamaktadır. $45^{\circ}$ 'lik eğik atış hareketi boyunca, mermiye ait konum, (mermi yörüngesine teğet olan $r$ ekseni doğrultusundaki) çizgisel hız ve açısal hız gibi değerler anlık olarak ölçülmektedir. Doppler radarı ile sürüklenme katsayısını sağlıklı olarak direk ölçebilmemiz mümkün değildir. Bunun için radardan gelen veriler aşağıdaki eşitlik yardımıyla hesaplatılarak veri toplama cihazı yardımıyla hıza bağlı sürüklenme katsayısı verileri bilgisayar üzerine yazılmıştır. Bu eşitliğin vektörel formu aşağıda verilmiştir [17].

$$
\mathrm{C}_{\mathrm{D}}=-\left[\left(\mathbf{u}_{\mathbf{r}}-\mathbf{w}\right) \cdot\left(\mathrm{d} \mathbf{u}_{\mathbf{r}} / \mathrm{dt}-\mathbf{g}-\boldsymbol{\Lambda}\right)\right] 8 \mathrm{~m} /\left(\pi \rho \mathrm{d}^{2} \mathrm{v}^{3}\right)
$$

Yukarıdaki vektörel eşitlikteki tüm vektörlerin referans sistemi, yeryüzüne tespit edilmiş, ortonormal ve sağ el kuralı ile uyumlu kartezyen koordinat sistemi olup birim vektörleri $\mathrm{x}$, $\mathrm{y}$ ve $\mathrm{z}$ doğrultularında sırasıyla 1, 2 ve 3 olarak verilirler. 1 ekseni, düşey eğik atış düzlemi ile ufuk düzleminin kesişiminde atış yönüne pozitif olarak; 2 ekseni, düşey ve yerçekimi

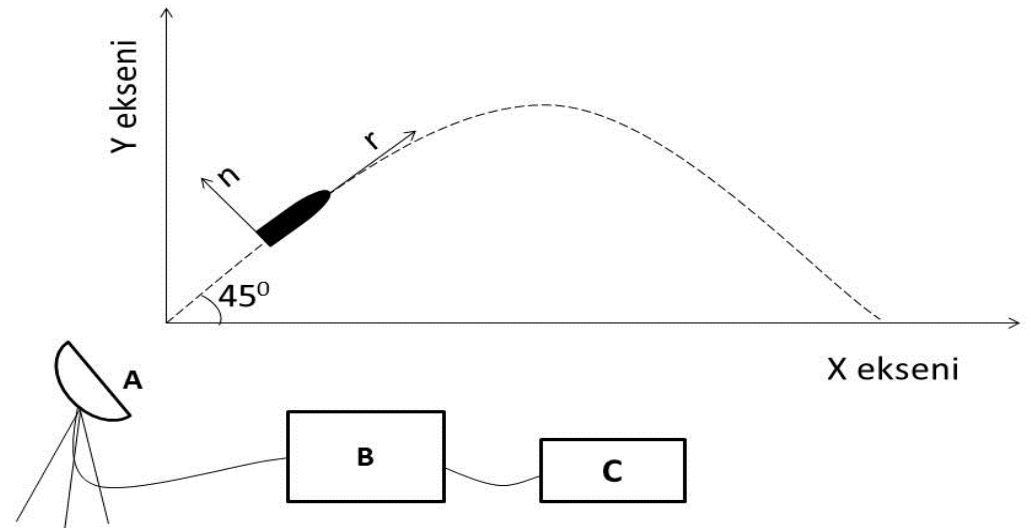

Şekil 1. Deney düzeneğinin şematik görünüşü (A-Doppler radarı, B-veri toplama sistemi,C-Bilgisayar) (A schematic view of the experimental setup (Doppler radar, B-Data gathering system, c-Computer))

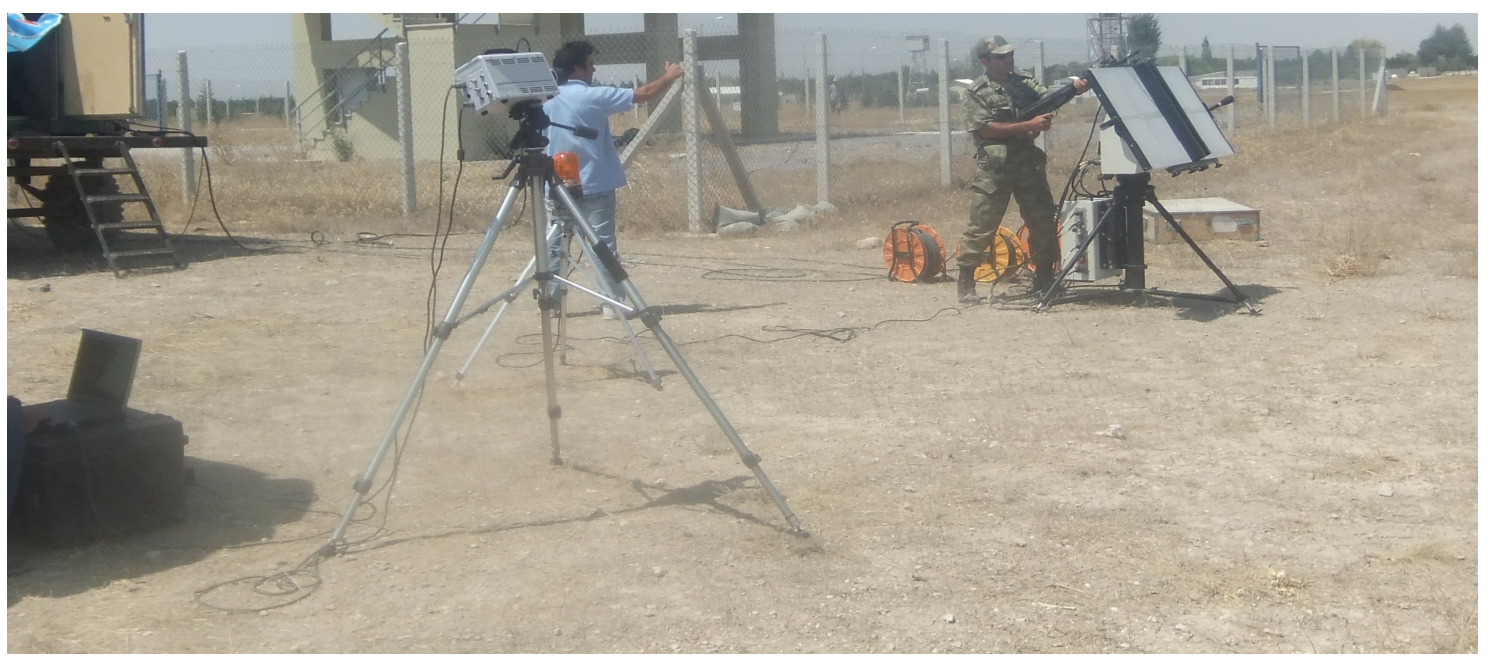

Şekil 2. Deney esnasında çekilmiş bir fotoğraf (A photo of the experimental setup taken during the experiments) 
ivmesi vektörüne paralel ancak ters yönde olarak; 3 ekseni, ufuk düzlemi içerisinde ve sağ el kuralına uyacak yönde verilirler. Burada $\boldsymbol{u}_{r}$, yeryüzüne tespit edilmiş koordinat sistemine nazaran Doppler radar verilerinden ve tahmini yörüngesinden belirlenen mermi hız vektörünü, $\boldsymbol{w}$ ölçüm sırasında ki yeryüzüne nazaran rüzgâr hızı vektörünü, $d \boldsymbol{u}_{\boldsymbol{r}} / d t$, yeryüzüne tespit edilmiş koordinat sistemine nazaran radar verilerinden ve tahmini yörüngesinden belirlenen mermi ivme vektörünü, $\boldsymbol{w}$ ölçüm sırasında ki yeryüzüne nazaran rüzgâr hızı vektörünü, $\boldsymbol{g}$ yer çekimi ivmesi vektörünü, $\boldsymbol{\Lambda}$ yeryüzünün koriyolis ivmesi vektörünü, $m$ merminin kütlesini, $\rho$ ortamdaki havanın yoğunluğunu, $d$ mermiye ait referans çapını ve $v$ ise merminin namluyu terk ettiği andan itibaren doppler radarı tarafindan ölçülen skalar hız değerini ifade etmektedir. Yukarıdaki büyüklüklerden $\boldsymbol{\Lambda}$ diğer büyüklüklerin yanında ihmal edilebilir mertebededir.

(1) vektörel eşitliğinin skalar formu gerekli sadeleştirmeler ve basitleştirici varsayımlar yapıldıktan sonra 1 ve 2 birim vektörleri cinsinden aşağıdaki hale getirilir.

$C_{D}=-\left[\left(u_{1}-w_{1}\right) d u_{1} / d t+u_{2}\left(d u_{2} / d t-g_{2}\right)\right] 8 m /\left(\pi \rho d^{2} v^{3}\right)$

(2) skalar eşitliği ilk defa R.F. Lieske ve A.M. Mackenzie tarafindan 1972 yılında yayınladıkları rapor ile kullanılmaya başlanmıştır [18]. (1) eşitliği günümüzde Doppler radarı ile yapılan deneysel ölçümlerde referans denklem olarak kabul edilmektedir [2].

\subsection{Doğrulama (Verification)}

Deneysel çalışma sonucunda çıkan değerlerinin doğrulaması için öncelikle daha önce aerodinamik testleri yapılmış 7,62x51 mm NATO mermisine ait referans kabul edilen değerler yaptığımız deneysel çalışma ve sayısal analiz ile karşılaştırılmıştır. Doğrulaması yapılan mermi geometrisi Şekil 3'teki gibidir.

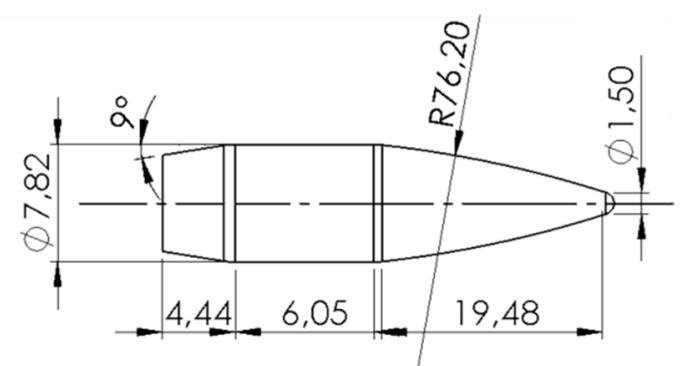

Şekil 3. $7,62 \times 51 \mathrm{~mm}$ mermi modeli (Geometry of the $7.62 \times 51 \mathrm{~mm}$ bullet model)

1988 yılında Robert L. McCoy tarafindan yayınlanan deneysel test sonuçları dünya üzerinde başta NATO mühimmatları olmak üzere $7,62 \mathrm{~mm}$ mermiler üzerinde yapılmış en kapsamlı çalışmalardan biri olarak nitelendirilmekte olup tüm dünya tarafindan referans değerler olarak kabul görmüştür [19].
Doğrulama amacı için bu referans değerler kullanılmış ve mevcut deneysel sonuç ile PRODAS programındaki analiz değerleri ile aşağıdaki şekilde karşılaştırılmıştır.

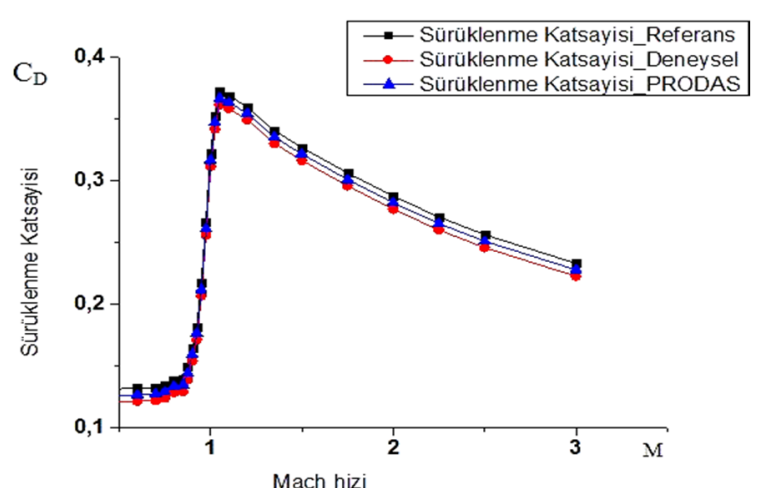

Şekil 4. 7,62 mm mermi için referans değer, deneysel sonuç ve PRODAS sonucu (Comparison of the drag coefficients of the $7.62 \mathrm{~mm}$ bullet obtained from reference values, calculated from experimental results and calculated from PRODAS results)

Şekil 4' te görüldüğü gibi sürüklenme katsayı için referans değer ile deneysel sonuç arasında ses hızına kadar aynı sonuçlar elde edilirken merminin ses hızını aşması ile birlikte \% 0,54 fark ile referans değerden daha az sonuçlar elde edilmiştir. Deney şartları açısından deneyin yapıldığı ortam, deneyde kullanılan namlunun aşınma değerlerinin farklığı, hava şartları gibi faktörlerden dolayı kabul edilebilir bir fark ile referans değerler, yapılan deneyde büyük oranda yakalanmıştır. PRODAS programı ile yapılan analizlerde ise referans değerlere deneysel değerlere oranla daha da yaklaşılmıştır. Buradan hareketle ilgili referans değerlerin hem deneysel yollarla hem de PRODAS programı ile büyük ölçüde yakalandığı hükmüne varılarak doğrulama işlemi tamamlanmıştır.

\subsection{Deney Parametrelerin Belirlenmesi (Determination of the Experimental Parameters)}

Şekil 3'te gösterilen mermi geometrisi üzerinde bazı geometrik değişiklikler yapılarak farklı formlara sahip mermi numuneleri hazırlanmıştır.

Parametreler belirlenirken mermiye ait temel ölçülerden, çap (D1), merminin orta gövdesinin başlangıcından fişek ile birleştiği noktaya olan uzunluk (L2) ve mermi radyüsünün başladığı yerden burundan önceki radyüs bitiş noktasına kadar olan uzunluk (Rt) değerleri muhafaza edilmiştir. Diğer tüm ölçüler değişken olarak alınmıştır. Tasarımsal olarak parametrelerin belirlenmesi sırasında, Şekil 2' de ki ölçülerden sadece bir ölçü değiştirilirken diğer ölçüler sabit tutulmuştur. Böylece mermi geometrisini oluşturan her bir bileşenin sürüklenme katsayısına olan etkisinin bireysel olarak araştırılması sağlanarak en küçük sürüklenme katsayısına sahip mermi geometrisi bulunması sağlanmıştır. Üretilen mermilere ait parametre Tablo 1'de gösterilmiştir. 
Tablo 1. Deney Numunelerine ait parametre ve ölçüler (Design parameters and dimensions of the experimental bullet samples)

\begin{tabular}{|c|c|c|}
\hline Numune Numaras1 & Değişken Adı & Ölçüsü \\
\hline 1 & $\theta$ & $4^{\circ}$ \\
\hline 2 & $\theta$ & $5^{\circ}$ \\
\hline 3 & $\theta$ & $6^{\circ}$ \\
\hline 4 & $\theta$ & $7^{\circ}$ \\
\hline 5 & $\theta$ & $8^{\circ}$ \\
\hline 6 & $\theta$ & $9^{\circ}$ \\
\hline 7 & $\theta$ & $10^{\circ}$ \\
\hline 8 & $\theta$ & $11^{\circ}$ \\
\hline 9 & L1 & $2,35 \mathrm{~mm}$ \\
\hline 10 & L1 & $3,13 \mathrm{~mm}$ \\
\hline 11 & L1 & $3,91 \mathrm{~mm}$ \\
\hline 12 & L1 & $4,69 \mathrm{~mm}$ \\
\hline 13 & L1 & $5,47 \mathrm{~mm}$ \\
\hline 14 & L1 & $6,26 \mathrm{~mm}$ \\
\hline 15 & D2 & $0,782 \mathrm{~mm}$ \\
\hline 16 & D2 & $1,172 \mathrm{~mm}$ \\
\hline 17 & $\mathrm{D} 2$ & $1,564 \mathrm{~mm}$ \\
\hline 18 & D2 & $2,0 \mathrm{~mm}$ \\
\hline 19 & $\mathrm{R}$ & $56,2 \mathrm{~mm}$ \\
\hline 20 & $\mathrm{R}$ & $66,2 \mathrm{~mm}$ \\
\hline 21 & $\mathrm{R}$ & $86,2 \mathrm{~mm}$ \\
\hline 22 & $\mathrm{R}$ & $96,2 \mathrm{~mm}$ \\
\hline
\end{tabular}

Mermilerin imal edildikten sonra atışa hazırlamak için fişek haline getirilmesi gerekmektedir. Bu işlem sırasında tüm fişeklerin aynı barut miktarıyla doldurulması temin edilmiştir. Bunun için barutlar fişeklere doldurulmadan önce hassas terazilerde tartılmış, ardından fişeklere eşit bir şekilde doldurularak mermiler atışa hazır hale gelmiştir.

\section{BULGULAR VE TARTIŞMA (RESULTS AND DISCUSSION)}

Parametreler belirlendikten sonra sürüklenme katsayısının mermi şekline bağlı olarak değişimi deneysel ve sayısal olarak incelenmiştir.

\subsection{Kuyruk Açısının ( $\theta)$ Sürüklenme Katsayısına} Etkisi $\left(C_{D}\right)$ (The Effect of the Tail Angle $(\theta)$ on the Drag Coefficient $\left(\mathbf{C}_{\mathrm{D}}\right)$ )

Ses altı hızda Şekil 5'te görüldüğü gibi kuyruk açısı $7^{\circ}$ ye yaklaştığında sürüklenme katsayısı en düşük olmaktadır.

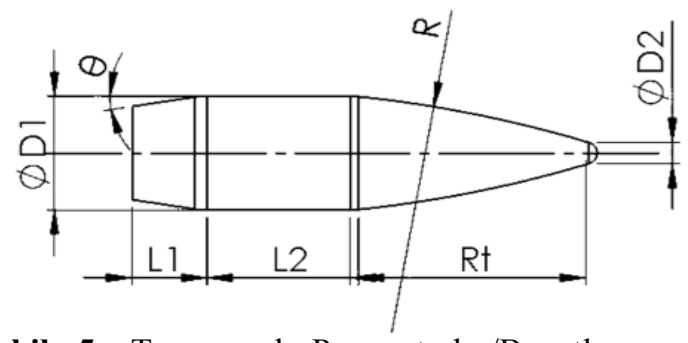

Şekil 5. Tasarımsal Parametreler/Boyutlar (Design parameters/dimensions of the bullet model)
Ses üstü hız olan 1,7 Mach hızında da kuyruk açısı $7^{\circ}$, ye yaklaştığında sürüklenme katsayısı azaltmakta bu açı değeri aşıldıktan sonra artmaktadır. Şekil 6 ve Şekil 7'den hareketle hem ses altı hem de ses üstü hızlar dikkate alındığında en düşük sürüklenme katsayısı için kuyruk açısının uygun değeri $7^{\circ}$ 'dir. 7 derecelik kuyruk açısının minimum sürüklemeye neden olmasının en önemli etmeninin, kuyruk açısının 7 derece olması halinde, merminin kuyruğunun ardındaki akış izi (wake) içerisinde oluşan girdapların (vortices) ve ses üstü hizlarda buna bağlı olarak şekillenen kuyruk şoklarının (tail shock waves) en kararlı hale kavuşmasının ve kuyruk yüzeyinin konumuna nazaran daha sabit (stable) bir formda kalmasının olduğu değerlendirilmektedir.

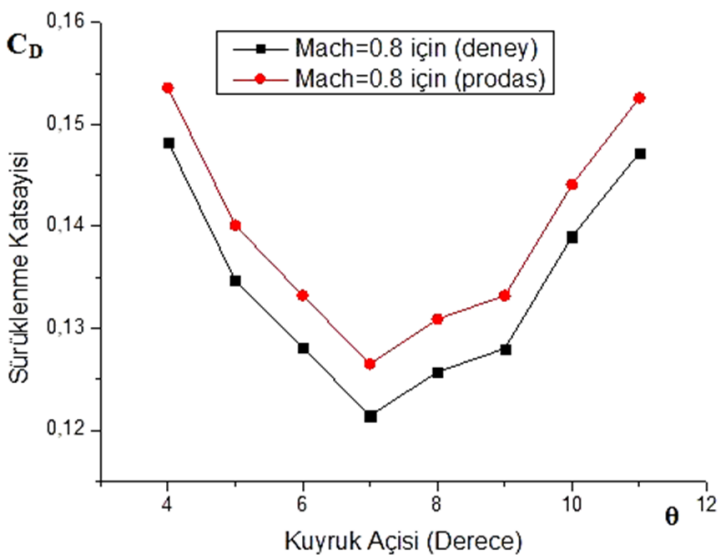

Şekil 6. 0,8 Mach hızda kuyruk açısının sürüklenme katsayısina etkisi (The effect of the tail angle on the drag coefficient at 0.8 Mach velocity 


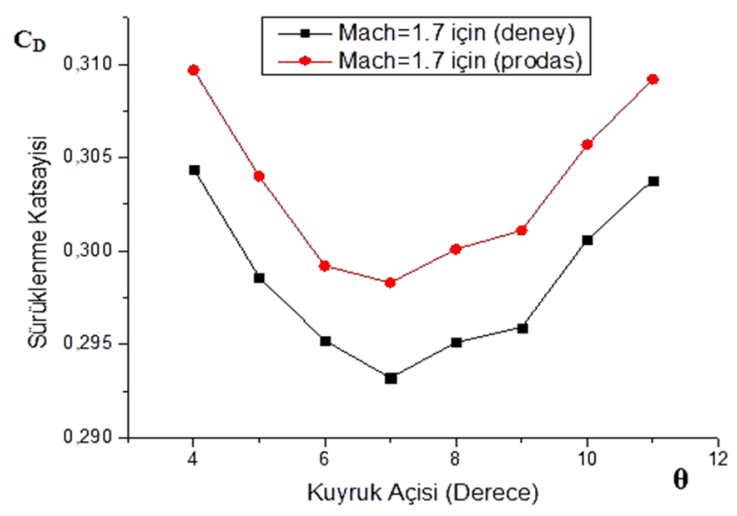

Şekil 7. 1,7 Mach hızda kuyruk açısının sürüklenme katsayısina etkisi (The effect of the tail angle on the drag coefficient at 1.7 Mach velocity)

Böylece akış izinin formuna ve büyüklügüne bağlı olan ve kaotik dalgalanmalarla artış gösterebilen sürükleme (both pressure and wave drags) minimize olmaktadır. İlaveten, kuyruk açısının 7 dereceden artması veya eksilmesinden dolayı merminin dönü kararlılığı da bozulmakta ve kararlılığın bozulmasının bir sonucu olarak mermi yalpalama hareketini yapmaya başlamaktadır. Başka bir deyişle, kararlı ve sabit akış izi formu, merminin dönü kararlılığını maksimize ederken yalpalamayı da minimize etmektedir. Aksi durumda yani kuyruk açısısının 7 dereceden daha düşük veya daha yüksek olması hallerinde, yukarıda anlatılan nedenlerden dolayı dönü kararlılığı azalıp mermi yalpalaması artarken, merminin akış izi formu da daha hızlı titreşmeye ve büyüklüğü dalgalanmaya başlamakta, dolayısı ile mermi üzerine etkileyen sürükleme katsayısı da artmaktadır.

3.2 Kuyruk Uzunluğunun (L1) Sürüklenme Katsayısına Etkisi $\left(C_{D}\right)$ (The Effect of the Tail Length (L1) on the Drag Coefficient $\left(C_{D}\right)$ )

Ses altı hız olan 0,8 Mach için Şekil 9'da gösterildiği gibi kuyruk uzunluğu arttıkça sürüklenme katsayısı azalmaktadır.

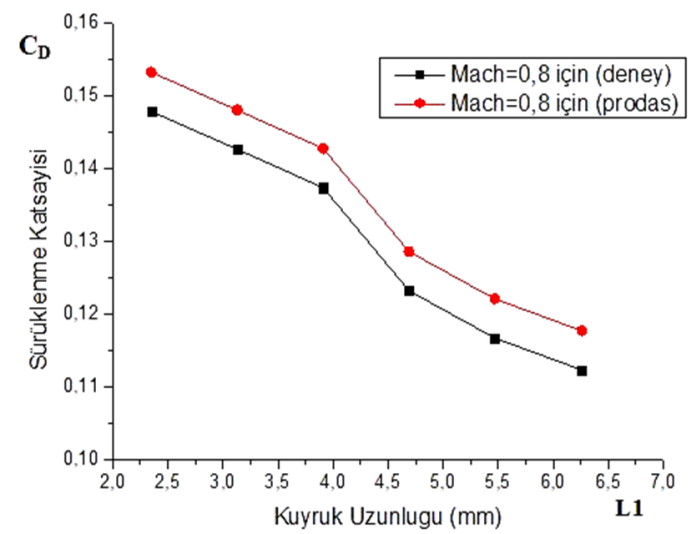

Şekil 8. 0,8 Mach hızda kuyruk uzunluğunun sürüklenme katsayısına etkisi (The effect of the tail length on the drag coefficient at 0.8 Mach velocity)

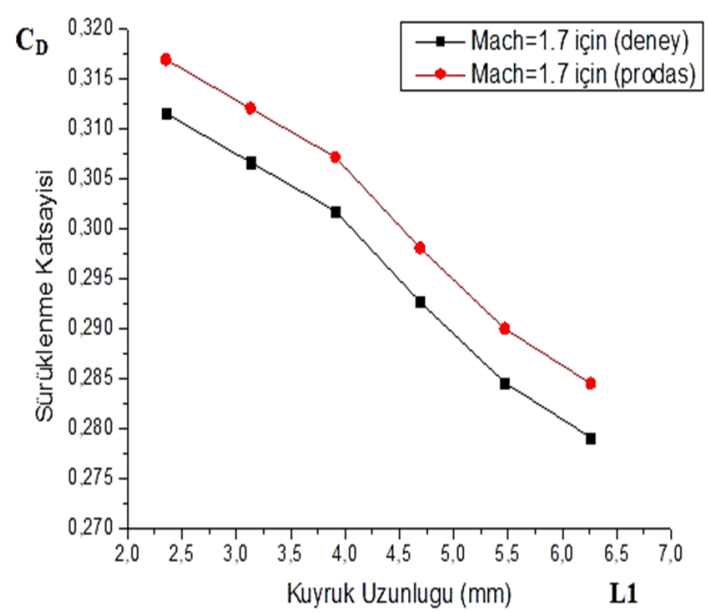

Şekil 9. 1,7 Mach hızda kuyruk uzunluğunun sürüklenme katsayısına etkisi (The effect of the tail length on the drag coefficient at 1.7 Mach velocity)

Kuyruk uzunluğunun artması ses altı hızda olduğu gibi ses üstü hızda da sürüklenme katsayısını düşürmüştür. Yalnız burada dikkat edilmesi gereken kuyruk uzunluğunun tasarımsal olarak mermi çapını aşması durumunda mermi için dengelenme problemi oluşmasıdır. Bunun sonucunda etkin menzil \% 40 oranında azalmaktadır. $\mathrm{Bu}$ yüzden mermi tasarımlarında bu değerin aşılması istenmez [2].

\subsection{Burun Çapının (D2) Sürüklenme Katsayısına Etkisi $\left(C_{D}\right)$ (The Effect of the Nose Diameter (D2) on the Drag Coefficient $\left.\left(C_{D}\right)\right)$}

Ses altı hızlarda en düşük sürüklenme katsayı için burun çapı değeri Şekil 10'da gösterildiği gibi 1,172 $\mathrm{mm}$ değeridir. $\mathrm{Bu}$ değerin üzerine çıkıldığında sürüklenme katsayı artmaya başlamıştır. Literatürde ki değerlere baktığımızda çapın 0,15 katı sürüklenme katsayı açısından en uygun değer olarak gözükmektedir.

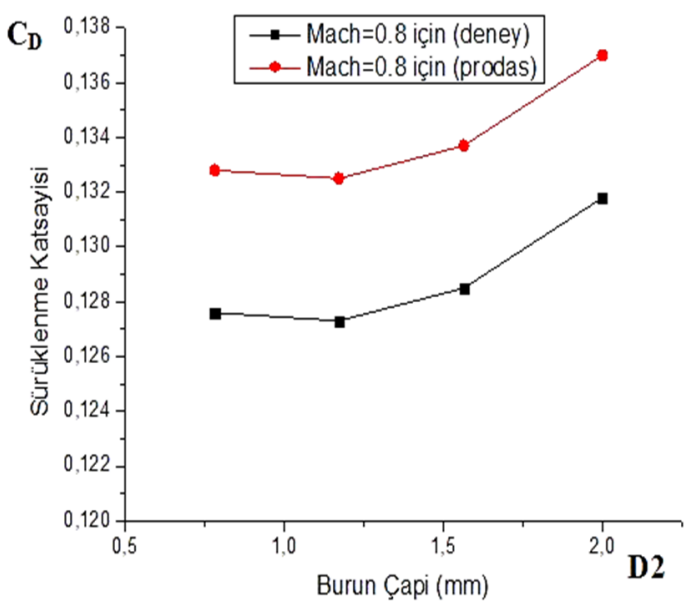

Şekil 10. 0,8 Mach hızda burun çapının sürüklenme katsayisına etkisi (The effect of the nose diameter on the drag coefficient at 0.8 Mach velocity) 


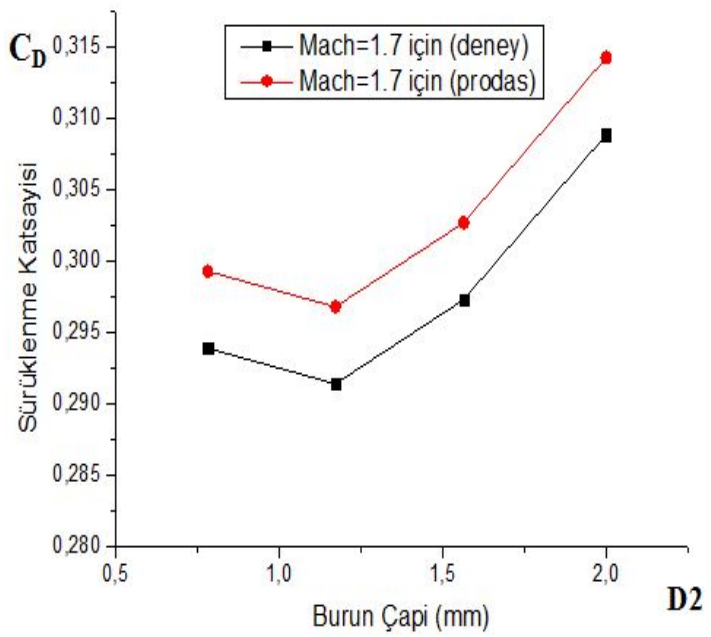

Şekil 11. 1,7 Mach hızda burun çapının sürüklenme katsayısına etkisi (The effect of the nose diameter on the drag coefficient at 1.7 Mach velocity)

Ses üstü hızlarda da ses altı hızlarda olduğu gibi 1,172 mm burun çapı için en düşük sürüklenme katsayısı bulunmuştur.

\subsection{Burun Radyüsünün $(\mathrm{R})$ Sürüklenme} Katsayısına Etkisi $\left(C_{D}\right)$ (The effect of the nose radius $(R)$ on the drag coefficient $\left(\mathrm{C}_{\mathrm{D}}\right)$ )

Sürüklenme katsayısına en çok etkileyen parametrelerden biride mermiye asıl şeklini veren burun radyüsüdür. Şekil 12'de görüldüğü gibi ses altı hızlarda burun radyüsü azaldıkça sürüklenme katsayısı azalmaktadır. Fakat burada dikkat edilmesi gereken bir başka özellikte mermilerin hedefte istenilen tahribatı meydana getirmesidir. Bunun için mermi radyüslerinde $65 \mathrm{~mm}$ altı tavsiye edilmez [2].

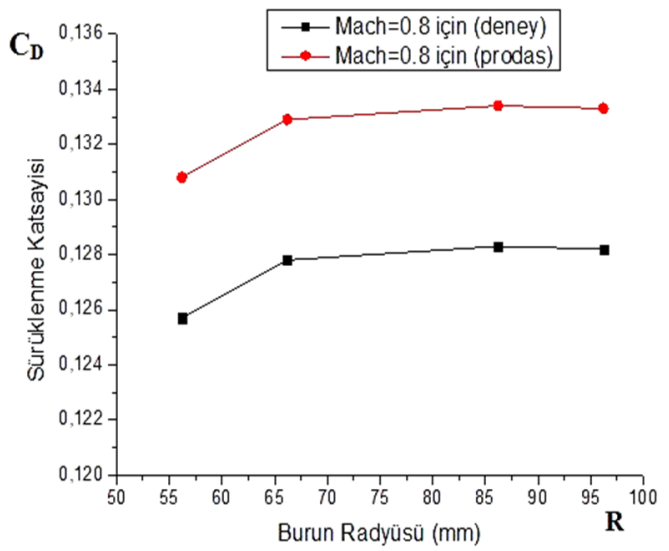

Şekil 12. 0,8 Mach hızda burun radyüsünün sürüklenme katsayısına etkisi (The effect of the nose radius on the drag coefficient at 0.8 Mach velocity)

Şekil 13'de ses altı hızdan farklı olarak ses üstü hızlarda burun radyüsü arttıkça sürüklenme katsayısı azalmaktadır. Merminin ses üstü hızlarda bu şekilde davranmasının nedeni, burun bölgesindeki konikliğin artmasının mermi burnu üzerine etkileyen şok dalgalarını azaltıcı etki yaratmasıdır.

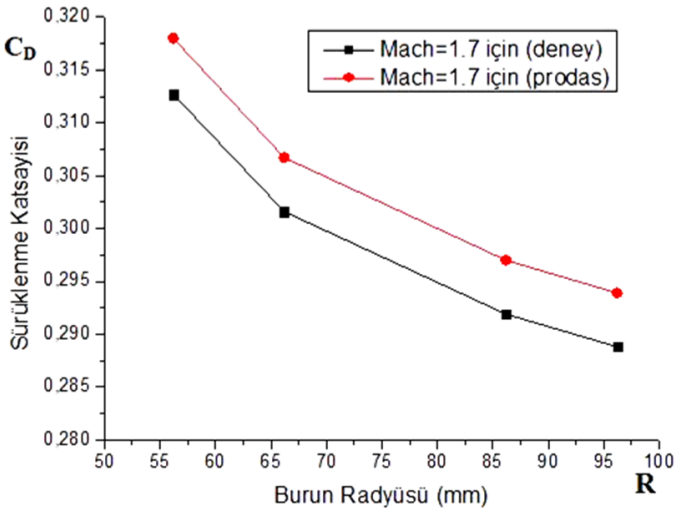

Şekil 13. 1,7 Mach hızda burun radyüsünün sürüklenme katsayısına etkisi (The effect of the nose radius on the drag coefficient at 1.7 Mach velocity )

\section{SONUÇLAR (CONCLUSIONS)}

Mevcut çalışmada 7,62 mm çaplı bir hafif silah mermisinin şekil faktörü açısından sürüklenme katsayısına etkisi deneysel ve sayısal olarak incelenmiştir. Deneysel ve sayısal sonuçlarının doğrulaması Şekil 3.'te 7,62×51 mm NATO mermisine ait referans değerler ile karşılaştırılarak gerçekleştirilmiştir. Elde edilen sonuçlar, referans değerlere çok yakın çıkmıştır. Deneysel doğrulamanın ardından 22 farklı mermi numunesi için deneysel ölçümler yapılmıştır. Ayrıca tüm mermi modelleri için balistik problemlerin çözümünde sıklıkla kullanılan PRODAS programı ile sayısal olarak analizler yapılmıştır. Deneysel ve sayısal parametrik çalışma toplu bir biçimde değerlendirilerek maddeler halinde bulgular ve yorumlar aşağıda sunulmuştur. Mevcut mermi geometrisinde kuyruk açısı $9^{\circ}$ dir. Deneysel ve PRODAS programı ile elde edilen sonuçlar (Şekil 6 ve Şekil 7) incelendiğinde $7^{\circ}$ 'lik bir açının sürüklenme katsayısı açısından daha uygun olduğu görülmektedir. Hem ses altı hem de ses üstü hızlarda $7^{\circ}$ 'deki sürüklenme katsayısı $9^{\circ}$ ye oranla daha düşük çıkmıştır. Kuyruk uzunluğu mevcut mermi geometrisinde 4,44 mm'dir. Yapılan deneysel ölçümler ve analizler sonucunda kuyruk uzunluğu arttıkça (Şekil 8 ve Şekil 9) ses altı ve ses üstü hızlarda sürüklenme katsayısının azaldığı görülmektedir. Fakat tasarımsal olarak kuyruk uzunluğu mermi çapını aştığında merminin ağırlık merkezi ile basınç merkezi arasındaki mesafe oldukça artacağından merminin havada kendi dönüsünden kaynaklı dengelenmesi azalacaktır. $\mathrm{Bu}$ nedenle mevcut mermi geometrisi için kuyruk uzunluğunun en fazla 7,82 mm çap değerine kadar arttırılmasının yararlı olacağ1 hükmüne varılmıştır. Burun çap1 sürüklenme katsayısını etkileyen önemli parametrelerden biridir. Özellikle mermi ses hızını aştığında üzerine gelen şok dalgalarını dağıtıcı özellikte olmalıdır. Bu nedenle burun çapı mevcut mermi geometrisinde 1,5 $\mathrm{mm}$ olarak tasarlanmıştır. Yapılan deneysel ölçümler ve PRODAS programı ile yapılan analizler sonucunda (Şekil 10 ve Şekil 11) $1,173 \mathrm{~mm}$ değerinin, ses üstü ve ses altı hızlarda en az 
sürüklenme katsayısı oluşturduğu görülmektedir. Sürüklenme katsayısına etkileyen bir diğer parametre de burun radyüsüdür. Mermiye ana şeklini veren bu değer, mevcut mermi için 76,2 mm'dir. Deneysel sonuçlar ve program ile yapılan analizlere bakıldığında 0,8 Mach için burun radyüsü arttıkça sürüklenme katsayısının arttığı görülmektedir. Fakat ses üstü hız olan 1,7 Mach için burun radyüsü arttıkça sürüklenme katsayısı azalmaktadır. Bunun en önemli nedeni, burun radyüsünün artmasının, ses hızını aştıktan sonra mermiye tesir eden şok dalgalarını mermi üzerinden daha rahat ve uzağa dağıtılmasını sağlayan bir etki yaratmasıdır. Sonuç olarak, 7,62x51 NATO mermisi üzerindeki kuyruk açısı, kuyruk uzunluğu, burun çapı ve burun radyüsü değerlerinin optimizesi sağlanırsa sürükleme katsayısı açısından daha uygun bir mermi tasarlanmış olacaktır. $\mathrm{Bu}$ açıdan bakıldığında, mermi üzerine gelen hava direnci azalacağından, sadece mermi geometrisi üzerinde iyileştirmeler yaparak aynı silahtan aynı barut miktarı ile merminin daha uzak mesafedeki hedefleri vurmasının mümkün olacağı değerlendirilmektedir.

\section{SEMBOLLER (NOMENCLATURE)}

$\mathbf{C}_{\mathbf{D}}$ : $\quad$ Sürüklenme Katsayısı

$\mathbf{u}_{\mathbf{r}}$ : Yeryüzüne tespit edilmiş koordinat sistemine göre mermi hız vektörü, [m/s]

w: Ölçüm sırasında ki rüzgâr hızı vektörü, [m/s]

$\mathbf{d u}_{\mathbf{r}} / \mathbf{d t}$ : Yeryüzüne tespit edilmiş koordinat sistemine göre mermi ivme vektörü $\left[\mathrm{m} / \mathrm{s}^{2}\right]$

р: $\quad$ Havanın yoğunluğu $\left[\mathrm{kg} / \mathrm{m}^{3}\right]$

m: Merminin kütlesi [ $\mathrm{kg}]$

d: $\quad$ Mermiye ait referans çap [mm]

v: Merminin doppler radarı tarafindan ölçülen havaya göre skalar hız değeri $[\mathrm{m} / \mathrm{s}]$

\section{KAYNAKLAR (REFERENCES)}

1. Carlucci, D.E. ve Jacobson, S.S., Ballistics:Theory and Design of Guns and Ammunition,CRC Press, Boca Rotan, A.B.D., 2014.

2. McCoy, R.L., Modern Exterior Ballistics, Schiffer, A.B.D., 2012.

3. Bashforth, F., A Revised Account of the Experiments Made with the Bashforth Chronograph, to Find the Resistance of the Air to the Motion of Projectiles, with the Application of the Results to the Calculation of Trajectories According to J. Bernoulli's Method, Cambridge University Press, İngiltere, 1890.

4. Becker, K. ve Cranz, C., Messungen Uber den Luftwiderstand für Grosse Geschwindigkeiten, Artilleristische Monatshefte, 1912.
5. Mayevski, ve Nikolai V., Trité Balistique Extérieure, Gauthier-Villars, Rusya, 1872.

6. Ingalls, J. M., Ingalls' Ballistics Tables, Artillery Circular M, A.B.D., 1900.

7. Hermann, E. E., Range and Ballistics Tables, A.B.D., 1926.

8. Hitchcock, H. P., Resistance Functions of Various Types of Projectiles, Ballistics Research Laboratories Report No 27, A.B.D., 1935.

9. Ballistic Tables, External Ballistics Department, Ordnance Board, War Ofice, England, 1940.

10. Murphy, C. H., On Stability Criteria of the Kelley-McShane Linearized Theory of Yawing Motion, Ballistics Research Laboratories Report, No 853, A.B.D., 1953.

11. Chapman, G. T. ve Kirk, D. B., A Method of Extracting Aerodynamic Coefficients from FreeFlight Data, AIAA Journal, Cilt 8, No 4, A.B.D., 1970.

12. Whyte, R. H., SPIN-73 An Updated Version of the SPINNER Computer Program, Picatinny Arsenal Contractor Report, TR-4588, 1973.

13. Nietubicz, C. J. ve Struek, W. B., Navier-Stokes Code Verification for Projectile Configurations at a Supersonic and Transonic Velocities, AIAA 15th Aerodynamic Testing Conference, A.B.D., 1988.

14. Cummings, R. M., Yang, H. T. ve Oh, Y. H., Supersonic, turbulent flow computation and drag optimization for axisymmetric afterbodies, Computers \& Fluids, Cilt 24, No 2, 487-507, 1995.

15. Chen, Y., Wen, C., Gong, Z. ve Sun, M., Drag coefficient curve identification of projectiles from flight tests via optimal dynamic fitting, Control Engineering Practice, Cilt 5, 627-636, 1997.

16. Wanchai, J., Chue, S. M., Nguyen, T., Pey, Y. Y., ve $\mathrm{Yu}, \mathrm{C}$. M., Aerodynamic characteristics of high performance rounds at Mach 1.8 to 4, Aerospace Science and Technology, Cilt 40, 62-74, 2015.

17. Lieske, R. F., Determination of Aerodynamic Drag and Ballistic Trajectory Simulation or the $155 \mathrm{~mm}$. DPICM, 864 Base-Burn Projectile, Ballistics Research Laboratory, Maryland, 1989.

18. Lieske, R. F. ve MacKenzie, A. M., Determination of Aerodynamic Drag From Radar Data, Exterior Ballistics Laboratory, Maryland, 1972.

19. McCoy, R. L., The Aerodynamic Characteristics of $7.62 \mathrm{~mm}$ Match Bullets, Ballistics Research Laboratory, Maryland, 1988. 